\title{
Mapping maternal and newborn healthcare access in West African Countries
}

Dorothy Ononokpono

University of Uyo

Bernard Baffour ( $\boldsymbol{Q}$ bernard.baffour@anu.edu.au )

Australian National University https://orcid.org/0000-0002-9820-2617

Alice Richardson

Australian National University

Research article

Keywords: Maternal and newborn health, districts, West Africa, mapping, geospatial analysis, buffer analysis.

Posted Date: August 13th, 2019

DOI: https://doi.org/10.21203/rs.2.11583/v2

License: (c) (1) This work is licensed under a Creative Commons Attribution 4.0 International License. Read Full License 


\section{Abstract}

Background: The Sustainable Development Goal (SDG) three emphasizes the need to improve maternal and newborn health, and reduce global maternal mortality ratio to less than 70 per 100000 live births by 2030. Achieving the SDG goal 3.1 target will require evidence based data on concealed inequities in the distribution of maternal and child health outcomes and their linkage to healthcare access. The objectives of this study were to estimate the number of women of reproductive age, pregnancies and live births at subnational level using high resolution maps and to quantify the number of pregnancies within userdefined distances or travel times of a health facility in three poor resource West African countries: Mali, Guinea and Liberia. Methods: The maternal and newborn health outcomes were estimated and mapped for the purpose of visualization using geospatial analytic tools. Buffer analysis was then performed to assess the proximity of pregnancies to health facilities with the aim of identifying pregnancies with inadequate access (beyond 50km) to a health facility. Results: Results showed wide variations in the distribution of maternal and newborn health outcomes across the countries of interest and districts of each of the countries. There was also clustering of health outcomes and health facilities at the urban capital cities of Bamako, Conakry, and Greater Monrovia. Conclusion: To bridge the gap in inequity in healthcare access, and improve maternal and newborn health in the study countries, there is need for equitable distribution of human resources and infrastructure within and across the various districts.

\section{Introduction}

Improvement in maternal and newborn health in developing countries has been a major priority in public health since the 1980s. This is reflected in the consensus reached at different international conferences, such as the Safe Motherhood conference in Nairobi in 1987 and the International Conference on Population and Development in Cairo in 1994, as well as specific targets in the Millennium and Sustainable Development Goals. In spite of these efforts to increase access to reproductive health services and reduce maternal mortality, maternal health is still poor in most developing countries. Globally, about 830 women die from pregnancy- or childbirth-related complications every day, and it was estimated that in 2015 , roughly 303000 women died during pregnancy and childbirth ${ }^{1}$. Unfortunately, almost all of these deaths (99\%) occurred in low-resource settings, and most could have been prevented with adequate access to healthcare. Although a number of countries in sub-Saharan Africa halved their levels of maternal mortality since 1990 , mortality rates for newborn babies have been slow to decline compared with death rates for older infants. The Sustainable Development Goals (SDGs), target 3.1, is to reduce the global maternal mortality ratio to less than 70 per 100000 live births by 2030 and improve maternal and child health.

For this target to be achievable and realised there has to be a concerted effort to improve the maternal and newborn health in low income countries, and in particular in the sub-Saharan African region. However, this requires accurate data for adequate planning of safer births and healthier newborns, which is difficult in these low-income countries due to poor vital registration information, and a lack of data on the geographical distribution of women of reproductive age. 
Also, subnational estimates of the projected future numbers of pregnancies are needed for more effective strategies on the allocation of human resources and infrastructure; and to assess coverage of services, there is a need to link information on pregnancies to travel distances for better information on health facilities in districts and regions ${ }^{2}$. Understanding the magnitude of inequities in health outcomes for both women and newborns is important in improving maternal and newborn health and services. Furthermore, the application of geospatial analysis and mapping of maternal and neonatal outcomes in relation to how close they are to health facilities is useful in identifying high priority areas or districts where women have low access to healthcare services; and also important in the fair distribution of these services ${ }^{3}$. Moreover, data visualization with the use of maps and geospatial analysis has been found to play an important role in addressing the need for improved maternal and newborn health service provision and access to emergency obstetric care at sub-national scale. In fact, geospatial analysis is highly recommended for application to maternal health programs in poor resource settings ${ }^{4}$.

Several studies using geospatial applications and mapping have focused on child mortality and childhood co-morbidity ${ }^{5,6}$; reviews on the importance of geospatial applications to maternal and newborn outcomes $^{7}$; and geographical factors within the vicinity of severe injury related to motor vehicle accidents $^{8}$. Others have examined the distribution of births and pregnancies in Afghanistan, Bangladesh, Tanzania Ethiopia and Ghana,2,9,10; health metrics and geography of maternal and newborn health ${ }^{11}$; spatial accessibility to health professionals in France ${ }^{12}$; geographic disparities in utilization of care in East African countries ${ }^{13}$; and spatial distribution patterns of healthcare facilities in Nigeria ${ }^{14}$. But to the best of our knowledge, studies on the estimation and mapping of maternal and newborn outcomes at subnational level and linkage to health facility access in poor resource settings in West Africa is sparse. In view of the fact that most births $(60 \%)$ take place at home and the burdens of disease and maternal and neonatal deaths are unacceptably high in most West African countries, this study is timely and adds to the body of knowledge through identifying districts with low maternal and newborn healthcare and access. This identification will inform decisions on appropriate maternal health policy and interventions in particularly disadvantaged districts.

Against this backdrop, this study examines spatial variability in the distributions of women of reproductive age, pregnancies and births in three West African countries (Mali, Liberia and Guinea) with a high burden of maternal and neonatal deaths. These three countries share borders, and given the porosity of borders in Africa (with communities of the same language group often separated by country borders), we can examine whether there are any differences in accessibility of maternal and newborn health services across neighbouring countries.

The objectives of the study were to describe and visualize the distribution of women of reproductive age, pregnancies and live births using high resolution maps and also quantify the number of pregnancies within user-defined distances or travel times of a health facility. This work has a distinct usefulness in health systems and policy through showing where there is demand for maternal and newborn health services. The estimates of proximities of pregnancies to health facilities link estimates of population in 
need with locations of facilities designed to meet this need ${ }^{15,16}$. Furthermore, the use of maps to display the results is a clear way of showing the spatial heterogeneity that exists at a subnational level and highlights geographic inequities in service provision ${ }^{17,18}$.

\section{Data And Methods}

This study utilizes publicly available WorldPop ${ }^{19}$ data derived from an integration of satellite, census and household survey data for three (3) West African countries, namely Mali, Liberia, and Guinea. The WorldPop dataset was constructed using the most recent and spatially detailed datasets available ${ }^{2}$. Detailed maps of settlement extents were derived from Landsat satellite imagery through either semiautomated classification approaches or expert opinion-based analyses ${ }^{20,21}$. These settlement maps were then used to refine land cover data. Additionally, local census data mapped at fine resolution enumeration area level from a random selection of countries across the continent were utilized to identify typical regional per-land cover population densities. These were subsequently applied to redistribute census counts to map human population distributions at $100 \mathrm{~m}$ grid square spatial resolution. Additional countryspecific datasets (where available), that provided data on population distributions not captured by censuses, were incorporated into the mapping process. Estimates of age and sex structures on subnational population compositions from the last 20 years were obtained from a variety of sources for the study countries. The datasets on numbers and proportions of individuals by age and sex were collated for as many subnational units as available within the last two decades, using sample weights where applicable to household surveys to provide aggregate estimates, and these were matched to corresponding geospatial datasets showing the boundaries of each unit. Africa-wide geospatial linked data on the number of individuals by age and sex within administrative unit were created. Furthermore, UN statistics and other sources on growth rates, age specific fertility rates, live births, stillbirths and abortions were then integrated to convert the population distribution datasets to gridded estimates of births and pregnancies.

In addition, information on health facilities was obtained from the Humanitarian Health Exchange $(\mathrm{HDX})^{22}$ and pre-processed for each country of interest. This data resource provides an open, accessible, and publicly available platform and repository to make health data easy to find and use for analysis. The Humanitarian Health Exchange collates information from various datasets from international and national organisations and business portals for the purpose of ensuring a coherent response to emergencies, and is managed by the UN's Centre for Humanitarian Data, under the auspices of the UN Office for the Coordination of Humanitarian Affairs (UN OCHA) ${ }^{23,24}$. The health facilities' information from the Humanitarian Health Exchange has to be geo-located and verified before being uploaded to the repository, through a quality assessment involving in-country experts ${ }^{24}$. This verification process provides an indication of the quality of the data assembled in the Humanitarian Health Exchange. In countries with good data infrastructure, not only is comprehensive geographic location information on health facilities available, but also available is information on their features and functions (e.g. number of doctors and nursing staff, services, care management and environment). This allows us to ascertain which health 
facilities can be determined to provide either basic or comprehensive emergency obstetric and newborn care (i.e. higher-level facilities with the capacity for caesarian section and blood transfusion). For our study countries, unfortunately, this is not readily available. We therefore, decided to restrict the listing of health facilities to include only those that met a stringent criteria of verifiability. This facilitated the compilation of an accurate though not comprehensive list of geocoded health centres that have the capacity to provide basic and emergency obstetric and newborn care, based on information from the Humanitarian Health Exchange for use in our analysis. After excluding those facilities that did not meet our criteria, the final analytic sample included 430 facilities (with 62 in Mali, 188 in Guinea, and 180 in Liberia). Finally, this list of health facilities was imported into ArcGIS software to use the latitude and longitude (geo-location) information to create a shapefile of health facilities throughout the study countries. The map situating the locations of the three study countries is provided in Figure 1, and in the next section, brief profiles of the countries are given.

\section{Mali}

Mali is a large landlocked country in the West African Sahel region, with a population of 18.5 million. It is one of the poorest countries in the world with a gross national product of approximately US\$2,160 per capita $^{25}$. Roughly three-out-of-five people (58\%) live in rural areas where roads, schools and health facilities are scarce, and it was estimated that less than $30 \%$ of the population lived within $10 \mathrm{~km}$ of a health facility in $1990^{26}$. Having children early in life exposes adolescent women to unnecessary risks: their chances of dying during childbirth is twice as high as that of women who wait until their twenties to begin childbearing ${ }^{27}$. In Mali, the adolescent birth rate per 1000 women aged 15-19 is 174 and this is second only to $\mathrm{Niger}^{28}$.

\section{Guinea}

Guinea has a population of 12.4 million. Its large deposits of mineral wealth (bauxite, gold, diamond) potentially makes Guinea one of the richest countries in Africa, but it still remains poor with a gross national income of US\$2,270 per capita, with $64 \%$ of the population living in rural areas ${ }^{29}$. In December 2013 it was the first country affected by an outbreak of the Ebola virus. Weak surveillance systems and poor public health infrastructure contributed to the difficulty in containing the outbreak, which meant that it quickly spread to Guinea's bordering countries of Liberia and Sierra Leone ${ }^{30}$. While there did not seem to be biological sex differences regarding vulnerability to Ebola, many of the sociocultural and healthcare related factors increased the risks for women ${ }^{31}$. The adolescent birth rate per 1000 women aged 15-19 is 146 and ranks fourth worldwide ${ }^{28}$.

\section{Liberia}

Liberia went through 14 years of civil conflicts which ended in 2004, but had a devastating effect on its population and infrastructure. Liberia is currently in recovery and rebuilding, and has one of the fastest growing populations in the world with a current population of 4.7 million $^{32}$. However, with a gross 
national income of US\$710 per capita, the majority of its population remain poor: it has been estimated that $84 \%$ of Liberians live below the international poverty line ${ }^{28}$. This has been made worse by the Ebola epidemic which overwhelmed the already fragile healthcare system ${ }^{33}$. Besides, one in three adolescent girls aged 19 in Liberia is either currently pregnant or already experiencing motherhood. Additionally, the adolescent birth rate is 149 per 1000 live births ${ }^{28}$.

\section{Maternal and Newborn Health in Mali, Guinea and Liberia}

The maternal mortality ratio (MMR) is a measure of risk of mortality due to pregnancy and childbirth, while neonatal mortality ratio (NMR) measures of the risk of mortality of newborns. Globally the risk of dying in the first 28 days of life is roughly 18 deaths per 1000 live births, while the global maternal mortality rate is 216 deaths per 100,000 live births. But these global figures do not show the disparities in different countries and regions. Table 1 shows the maternal mortality ratio and neonatal mortality rate for the three countries included in the study. For comparative purposes we also present the rates for SubSaharan Africa (excluding high income countries) and the Euro-zone area (comprising of the $19 \mathrm{EU}$ member states that share the common currency), over the period from 1990 to 2015 . While these show the general pattern of improved health access leading to lower rates of mortality (with reductions of roughly $50 \%$ over the 15 year period), there are remarkable differences between the sub-Saharan region and the Euro-zone area maternal and neonatal statistics. Although there have been reductions in the rates over time, the levels of neonatal and maternal mortality in the study countries remain unacceptably high. The rates in the Euro-zone area are roughly 100 times smaller than in sub-Saharan Africa. Further, the three study countries all have higher maternal and neonatal mortality than the sub-Saharan (average) rate, highlighting that women and children in these countries in fact experience worse outcomes than others within the sub-Saharan African region.

Table 1 - Maternal and Neonatal health statistics for the study countries

\begin{tabular}{lrrr}
\hline & & $\mathbf{1 9 9 0}$ & $\mathbf{2 0 1 5}$ \\
\hline Mali & MMR & 1010 & 587 \\
& NMR & 72.8 & 36.8 \\
\cline { 2 - 4 } Guinea & & & \\
& MMR & 1040 & 679 \\
Liberia & NMR & 61.7 & 25 \\
\hline \multirow{2}{*}{ Sub-Saharan Africa (excluding high income) } & MMR & 1500 & 725 \\
\cline { 2 - 4 } & NMR & 58.4 & 26.3 \\
\hline \multirow{2}{*}{ Euro-zone area } & NMR & 45.7 & 547 \\
& MMR & 11 & 28.5 \\
& NMR & 4.8 & 6.3 \\
\hline
\end{tabular}

Notes:

Source - World Development Indicators ${ }^{34}$. 
MMR is the maternal mortality ratio per 100,000 live births. NMR is the neonatal mortality rate per 1,000 live births.

\section{Analytical methods}

This study uses exploratory spatial data analysis techniques to estimate and visualize the spatial distribution of women of reproductive age (15-49), but with a focus on live births and pregnancies to women aged 15-19 and 40-44 years old. The choice of women in these two age groups in this study was due to the fact that they are women at most risk during pregnancy and childbirth complications due to young age or old age. Data were analyzed using ArcGIS version 10.6. We utilized the clip function tool to extract the age structure dataset of each of the three countries of interest from the high resolution agestructured population distribution map of Africa, while maintaining the clipping geometry and extent of the district administrative maps.

These high resolution maps of age structure, births and pregnancies were then uploaded into ArcGIS to obtain the number of women of 'at risk' reproductive age (i.e. aged 15-19 and 40-44 years old), live births and pregnancies per $100 \mathrm{~m} \times 100 \mathrm{~m}$ grid square. To examine the distribution of the outcome variables, we use descriptive chloropeth maps using the ArcGIS software to obtain the number of women of reproductive age, live births and pregnancies per grid square. These chloropeth maps use shading in proportion to the magnitude of the outcome variable to highlight areas with high prevalence (lighter shades represent low prevalence while darker shades represent high prevalence), and thereby can be used to visualize the spatial distribution and identify inequities.

Buffer analysis was then performed to quantify the proximity of pregnancies to health facilities. The buffer is a zone of specified radius or width around a selected map feature or raster of grid cells measured in distance. This geographic location or buffer zone allowed us to estimate the proximity of pregnancies to health facilities through calculation of distances to the nearest health facility. Following the methodology developed by WorldPop project ${ }^{2}$, we then created buffers of $50 \mathrm{~km}$ radii around each facility since this is approximately equivalent to 2 hours travel time by motorized transport (based on the standard yardstick used for national disparity assessment of access to health services for international comparison ${ }^{35}$ ). This is based on the well-established link between travel distance and health access, and the fact that travelling further is associated with health outcomes, particularly in terms of pregnancy and childbirth.

These buffer zones were then overlaid to each country's pregnancy dataset and the numbers within the $50 \mathrm{~km}$ buffer calculated to obtain an estimate of pregnancies with 'access to (adequate) maternal healthcare'. In contrast, the number of pregnancies residing outside these buffers provided an indication of those 'without (adequate) access'. 
The percentage of pregnancies that fell within and outside $50 \mathrm{~km}$ of a health facility was calculated using the erase, clip and zonal statistics tools in ArcGIS; and the results were mapped to provide an understanding of the geographic and spatial variation of health accessibility and highlight inequities in maternal health service provision. In simple terms, this measure of proximity is used map the areas with women and babies at risk due to having to travel more than two hours in order to access life-saving interventions. Since the choice of a $50 \mathrm{~km}$ buffer zone did not fully represent the difficulty of travel between two locations (for this we would require impedance information that would reflect the most efficient route to the nearest health facility ${ }^{35}$ ), we undertook the same calculation of distances but created buffers of $25 \mathrm{~km}$ radii (equivalent to 1 hour travel in motorised transport). Through comparing both sets of results, we can obtain an indication of the distribution of healthcare accessibility and identify any areas where there are persistent spatial inequalities in access to life-saving maternal and newborn health services.

To provide useful interpretative results from the buffer analysis we grouped districts within regions. We first computed the proportion of pregnancies and births that were within $50 \mathrm{~km}$ (and $25 \mathrm{~km}$ ) of health facilities, and summed these at a regional level to take account of any spatial heterogeneity effects due to small numbers. Through this analysis we can visualize the distribution of pregnancies, births and health accessibility, and identify locations with clusters of live births and 'at risk' women, at sub-regional levels of geography (these are districts in Mali and Liberia and prefectures in Guinea). We will now provide some information to familiarize the reader with the unique geographical and administrative context of each country. Mali is divided into ten regions, and one capital district (the Bamako district). Each of these regions are divided into 56 districts referred to as 'cercles'. Guinea is divided into 8 administrative regions which are further divided into 34 sub-regions known as 'prefectures'. Liberia is divided into 15 administrative regions, referred to as counties. These counties are divided into 108 districts. Figure 2 shows the administrative geographical divisions for each of the three study countries.

\section{Results}

\section{Spatial distribution of women of reproductive age 'at risk' of pregnancy related complications (young women: aged 15-19 and old women: aged 40-44 years old).}

Results from zonal statistics and the visual maps indicated considerable spatial heterogeneities in the distribution of women of reproductive age per square kilometre across the urban districts of Mali, Guinea, and Liberia. The highest concentration of at risk pregnancies was found in the respective metropolitan capital areas of Bamako, Conakry and Greater Monrovia. In Mali, the distribution of women aged (15-19) per grid square kilometre was high in Bamako (717), Gao (1029) in the Gao region, located in the north, Koulikoro (541) and Kayes district (506), both located in the Kayes region in western Mali, along the Senegal River. The lowest maximum number of young reproductive age women per grid kilometre was found in almost all the districts in Kidal region, Meneka (14) in Gao region, Nara (15) in Koulikoro region in the west; and Youwarou (17) in Mopti region, central Mali (these districts are shown in darker red shades in Figure 3a). These results make sense since most of these areas are in the sparsely populated 
desert regions of Mali. A similar spatial pattern was observed for the older reproductive age women (4044) (shown in pink shades in Figure 3b).

In Guinea, the maximum number of young women of reproductive age per grid square was high in Conakry (1481) and the prefectures of Macenta (329) in the Nzerekore region in the south; Kissindougou (306) in Faranah region in central part of Guinea and Toungue (910), located in Labe region in the northern part of the country (these districts are presented in dark blue shade in Figure 3c). The distribution of women aged 40-44 followed similar pattern. However, the maximum number of women per grid kilometre was lowest in northern Guinea and varied from 33 in Dubreka (Kindia region), 42 in Pita (Mamou region) to 62 in Lélouma (Labe region). Results also showed a low distribution in Boffa (39) located in the Boke region, in western Guinea (districts shown in light brown shades in Figure 3d).

For Liberia, the districts with the highest clustering of 'at risk' young reproductive aged women per grid kilometre include Greater Monrovia (877), St Paul River (759), Pleebo/Sodeken in Maryland (529) and Greenville (460) in Sinoe county in the south. These areas are the more densely populated regions of Liberia. In contrast, the lowest distribution of women of reproductive age was observed in Mecca district in Bomi county (7), Zota (6) in Bong county, Bokomu (5) and Kongba (in the Gbarpolu county), Morweh (5) Butaw (4) and Kpayan (4). These districts located in the forested regions in south-central and northern Liberia are in the sparsely populated areas of the country. The results for older (40-44) aged women exhibited similar patterns. (To see this visually, these districts shown are in yellow and light purple shades in Figure $3 e$ and f).

\section{Spatial distribution of Live Births}

For the spatial distribution of births, there were clusters of live births in the capital cities of Mali, Guinea and Liberia, as can be expected due to the large population resident in the urban capital areas. In Mali, the minimum number of live births per $\mathrm{km}^{2}$ was as low as zero (0) in all the districts shown in light blue colour (Figure 4a), and high in districts shown in deep blue colour. Meanwhile there was a clustering of live births in Bamako, with a minimum of 10 and maximum of 491 live births per $\mathrm{km}^{2}$. The highest maximum number of live births per $\mathrm{km}^{2}(1,063)$ was observed in Gao district (Gao region) in the northern part of Mali.

The maximum number of live births per squared kilometre in Guinea was high for: Nzerekore in Nzerekore region, Mandiana in Kankan region and Tougue in Labe region and was highest in Conakry with a maximum of 756 live births per square kilometre (see Figure 4b, districts in purple colour). Districts in light green shade had the lowest estimated number of births and these include: Boffa in Boke region, Dubréka in Kindia region and Pita in Mamou region located in a valley of the Fouta Djallon area of in central Guinea. These regions of Guinea are characterized by a high degree of migration to neighbouring countries.

In Liberia, the highest number of births per square kilometre (407) occurred in Greenville in Sinoe county, located in south-east Liberia, and shown in Figure $4 \mathrm{c}$ as the districts in deeper shades of blue. Other 
districts with high births include Greater Monrovia and St Paul River in Montserrado county, SanniquellehMahn and Tappita in Nimba county, Pleebo/Sodeken in Maryland, District 3 in Grand Bassa county, and Mambah-Kaba in Margibi county. To a large extent there is a high level of correspondence between these districts and the earlier results of the spatial distribution of 'at risk' reproductive aged women. This is to be expected: areas with more women can be expected to have more births, on average. Contrastingly, the districts with the less than five estimated births (per square kilometre) include District 2 (Grand Bassa county), Bokomu and Kongba (in Gbarpolu region), Kokoyan (in Bong county), Salayea (in Lofa county), Buah and Sasstown (in Grand Kru county), Morweh (Rivercess county), Butaw and Kpayan (both in Sinoe county). These are districts in sparsely populated areas of the country (as shown in the lighter shades of yellow in Figure 4c)

While understanding the spatial patterns of reproductive aged women and live births were important, we are specifically interested in examining the distribution of pregnancies - for the reason that not all pregnancies result in live births. Through understanding the spatial patterns of pregnancies we can next quantify the proximity of pregnant women to health facilities, and this will provide us with a measure of access to obstetric healthcare.

Broadly speaking, there appears to be clustering of pregnancies in all the urban capital cities of the three countries of interest (Figure 5). For Mali, the estimated number of pregnancies was higher in areas with blue colour with a maximum of 1421 pregnancies per grid square in Gao district (Gao region). This region has been rapidly growing, with a large urban settlement developing along the Niger River. Other districts with high number of pregnancies per grid square in Mali were Kita and Kayes (in Kayes region), Koulikoro and Kati (in Koulikoro region) in western part of Mali, San (in Segou region) located in South central Mali, Mopti (in Mopti region), located at the confluence of the Niger and the Bani Rivers, Sikasso in Sikasso region in the southern-most part of Mali and Timbuktu in Northern Mali, located at the southern edge of the Sahara desert. For Guinea, Gousal and Fria (in Boke region), Kissidougou (in Farana region), Mandiana (in Kankan region) and Nzerekore (in Nzerekore region) respectively had higher estimated number of pregnancies, while the highest maximum number of 1012 pregnancies per grid square occurred in Conakry. In Liberia, the districts in dark pink colour (Figure 5c) had the highest cluster of estimated pregnancies per grid square and these include Greater Monrovia (490 births), Greenville (545 births), and Pleebo/Sodeken (421 births) - all of these areas are located in the Southern counties of Sinoe and Maryland respectively.

\section{Quantifying the proximity of pregnancies to health facilities}

After mapping the spatial variation in the pregnancies, we undertook a buffer analysis to measure the proximity of pregnant women to health facilities. Results of the buffer analysis for Mali revealed disparities in health facility coverage and access in many districts. As shown in Table 2, all the pregnancies in Bamako were within $50 \mathrm{~km}$ and $25 \mathrm{~km}$ of a health facility indicating adequate access. In contrast, all the pregnancies (100\%) in Kidal region were outside $50 \mathrm{~km}$ (and consequently also outside 
$25 \mathrm{~km}$ ) in distance to a health facility, implying that pregnant women had to travel more than 2 hours to access healthcare services.

Table 2: Number of pregnancies (and percentage) outside $50 \mathrm{~km}$ and $25 \mathrm{~km}$ of a health facility in Mali in 2015 by region

\begin{tabular}{|l|l|l|l|}
\hline Regions & $\begin{array}{l}\text { Total Number of } \\
\text { Pregnancies* }\end{array}$ & $\begin{array}{l}\text { Pregnancies outside 50km } \\
\text { buffer zones } \\
\mathrm{N} \quad(\%)\end{array}$ & $\begin{array}{l}\text { Pregnancies outside 25km } \\
\text { buffer zones } \\
\text { N }\end{array}$ \\
\hline Bamako & 102551 & $0 \quad(0)$ & 0 \\
\hline Gao & 43281 & $25136(58.1)$ & $29780(68.8)$ \\
\hline Timbuktu & 60272 & $49744(82.5)$ & $54391(90.2)$ \\
\hline Segou & 143013 & $81944(57.3)$ & $113612(79.4)$ \\
\hline Mopti & 138333 & $99119(71.6)$ & $108718(78.5)$ \\
\hline Kayes & 130906 & $93117(71.1)$ & $110791(84.6)$ \\
\hline Sikasso & 185891 & $100256(53.9)$ & $143617(77.2)$ \\
\hline Koulikoro & 162069 & $99870(61.6)$ & $118898(73.4)$ \\
\hline Kidal & 5099 & $5099(100)$ & $5099(100)$ \\
\hline
\end{tabular}

*Total number of pregnancies per region is the sum of pregnancies in all the districts in the region

There was some additional spatial variation in access based on the region the women were located in. In Timbuktu the majority of pregnancies (83\%), over two-thirds in Mopti (72\%) and Kayes (71\%), and more than half in Koulikoro (62\%) and Gao (54\%) were outside $50 \mathrm{~km}$ of a health facility. Similarly, more than three-quarter of pregnancies in the districts of Timbuktu (90\%), Segou (79\%), Mopti (79\%), Kayes (85\%) and Sikasso $(77 \%)$ were outside $25 \mathrm{~km}$ buffer zones, while over two-thirds of pregnancies in Gao $(69 \%)$ were outside $25 \mathrm{~km}$ distance of a health facility.

The visual maps (Figures 7a, b) and zonal statistics (Table 3) showed spatial variations in health facility access across the various districts of Guinea. Estimates from the zonal statistics indicated that 100 percent of the estimated pregnancies in Conakry were within $25 \mathrm{~km}$ of a health facility. Out of all the pregnancies outside $50 \mathrm{~km}$ and $25 \mathrm{~km}$ buffer zone, the highest percentages were observed in Mamou region ( $46 \%$ and $89 \%)$ Labe $(39 \%$ and $62 \%$ ) respectively.

Table 3: Number of pregnancies (and percentage) outside $50 \mathrm{~km}$ and $25 \mathrm{~km}$ of a health facility in Guinea in 2015 by regions 


\begin{tabular}{|c|c|c|c|c|c|}
\hline Region & $\begin{array}{l}\text { Total number of } \\
\text { pregnancies }\end{array}$ & $\begin{array}{l}\text { Pregn } \\
50 \mathrm{kr} \\
\mathrm{N}^{-}\end{array}$ & $\begin{array}{l}\text { ies outside } \\
\text { uffer zones } \\
(\%)\end{array}$ & $\begin{array}{l}\text { Pregna } \\
\text { buffer } \\
\mathrm{N}\end{array}$ & $\begin{array}{l}\text { ies outside } 25 \mathrm{~km} \\
\text { les } \\
(\%)\end{array}$ \\
\hline Conakry & 75514 & 0 & $(0)$ & 0 & $(0)$ \\
\hline Boke & 60900 & 15187 & $(24.9)$ & 35715 & (58.6) \\
\hline Farana & 46342 & 5442 & $(11.4)$ & 14785 & (31.9) \\
\hline Mamou & 38749 & 17896 & $(46.0)$ & 34572 & $(89.2)$ \\
\hline Kankan & 102356 & 14776 & (14.4) & 51621 & $(50.4)$ \\
\hline Kindia & 91915 & 4397 & $(4.7)$ & 11169 & $(12.2)$ \\
\hline Labe & 46330 & 18256 & (39.4) & 28692 & $(61.9)$ \\
\hline Nzerekore & 129521 & 15792 & $(12.2)$ & 33205 & $(25.6)$ \\
\hline
\end{tabular}

Results also revealed that one out of every four pregnancies in Boke (25\%) was not within $50 \mathrm{~km}$ of a health facility and the lowest percentage (5\%) was found in Kindia. For pregnancies outside $25 \mathrm{~km}$ buffer zone, about 3 out of 5 occurred in Labe (62\%) and Boke (59\%), half in Kanakan (50\%), one third in Farana $(32 \%)$ and 1 out of 4 in Nzerekore (26\%).

Table 4: Number of pregnancies (and percentage) outside $50 \mathrm{~km}$ and $25 \mathrm{~km}$ of a health facility in Liberia in 2015 by regions

\begin{tabular}{|l|l|l|l|}
\hline Regions* & $\begin{array}{l}\text { Total number of } \\
\text { pregnancies }\end{array}$ & $\begin{array}{l}\text { Pregnancies outside 50km } \\
\text { Buffer zones } \\
\text { N (\%) }\end{array}$ & $\begin{array}{l}\text { Pregnancies outside 25km } \\
\text { buffer zones } \\
\text { N (\%) }\end{array}$ \\
\hline Gbarpolu & 5264 & $144(2.7)$ & $1161(22.1)$ \\
\hline $\begin{array}{l}\text { Grand } \\
\text { Gedeh }\end{array}$ & 9627 & $1300(13.5)$ & $3821(39.6)$ \\
\hline $\begin{array}{l}\text { Grand } \\
\text { Kru }\end{array}$ & 4640 & $145(3.1)$ & $2398(51.6)$ \\
\hline Nimba & 30828 & $55(0.2)$ & $3130(10.2)$ \\
\hline $\begin{array}{l}\text { River } \\
\text { Gee }\end{array}$ & 4595 & $172(3.7)$ & $1606(34.9)$ \\
\hline Rivercess & 4965 & $83(1.6)$ & $2094(42.2)$ \\
\hline Sinoe & 7241 & $10(0.1)$ & $2840(39.2)$ \\
\hline Bong & 19639 & $0(0)$ & $66(0.3)$ \\
\hline Lofa & 14405 & $0(0)$ & $3666(25.4)$ \\
\hline Margibi & 17016 & $0(0)$ & $258(1.5)$ \\
\hline
\end{tabular}

Note: *Only regions with pregnancies outside $50 \mathrm{~km}$ and $/$ or $25 \mathrm{~km}$ of a health facility are displayed

The percentage of estimated pregnancies outside $50 \mathrm{~km}$ distance to a health facility in Liberia was highest in Grand Gedeh (14\%) lowest in Sinoe. Meanwhile in Bong, Lofa and Margibi regions, all the 
pregnancies were within $50 \mathrm{~km}$ radius. More than half (52\%) in Grand Kru, roughly 2 out of 5 pregnancies in Rivercess (42\%), Sinoe (39\%) and Grand Gedeh (40\%), and one-quarter in Lofa (25\%) and slightly over one-third in River Gee (35\%) and were outside $25 \mathrm{~km}$ buffer zone. The lowest percentage $(0.3 \%)$ was found in the Bong region.

\section{Discussion}

The focus of this study was to describe and visualize the spatial distribution of women of reproductive age, pregnancies and live births at subnational levels in Mali, Guinea and Liberia, and to quantify and identify pregnancies with inadequate access to healthcare services (those that fell outside $50 \mathrm{~km}$ and $25 \mathrm{~km}$ of a health facility). The results revealed spatial heterogeneities in in the distribution of women of reproductive age, births and pregnancies across the districts, and clustering of all the estimated reproductive health outcomes in the urban and capital cities of the three countries: Bamako, Conakry and Monrovia. Buffer analysis also revealed that all the estimated pregnancies $(100 \%)$ were within $50 \mathrm{~km}$ and $25 \mathrm{~km}$ of a health facility indicating adequate coverage and access. This could be due to environmental features and high concentration of health facilities in the capital cities. We will now discuss the country results one at a time: Mali, Guinea, then Liberia.

In Mali, the distribution of women of reproductive age, births and pregnancies per grid $\mathrm{km}$ was highest in Bamako, Gao, Koulikoro, Kayes and Segou districts in Northern and southern Mali; and lowest in districts of Timbuktu, Gao and Kidal regions in the North. In addition, the results of our study showed that 100 percent of pregnancies in all the districts of Kidal region, and more than 70 percent in Timbuktu, Mopti and Kayes regions were not within $50 \mathrm{~km}$ and $25 \mathrm{~km}$ distance to a health facility. This is not surprising because, the armed conflict that has been going on in the Sahel may have contributed to the difficulty in accessing healthcare for women and newborn living in the north.

According to International Committee of the Red Cross (ICRC) report, the conflict has affected the functioning of health facilities, hence it is very hard for many Malians, particularly young children and pregnant women, who are the most vulnerable segment of the population and also war casualties, to obtain adequate access to healthcare ${ }^{36}$. Apart from four community health centres in the Bourem district to the north of Gao and a referral health centre in Kidal, Gao's regional hospital remains the main medical facility in the north of the country. Our study corroborates the findings of this report, as all the pregnancies in the districts of Kidal were outside $50 \mathrm{~km}$ distance of a health facility. This implied that pregnant women would have to travel over 50 kilometres (approximately over 2 hours) from other rural districts in order to access care in the Gao region. The ICRC report also confirmed that women in labour were often arriving too late from the rural areas with complications of bleeding thus leading to high rate of infant and maternal mortality at the hospital in $\mathrm{Gao}^{36}$. There is therefore need for the provision of adequate primary healthcare and health professionals in the districts of northern Mali.

In Guinea, (as shown in Figures 3a and b; $4 b$ and $5 b$ ) high clusters of women of reproductive age, live births and pregnancies were observed in the capital city of Conakry and most districts in Nzerekore, Labe 
and Farana regions. However, the lowest distribution of women of reproductive age was found in the districts of Siguiri and Mandiana in Kankan region; Gousal, Boffa and Koundara in Boke region located in Western Guinea; Dinguiraye in Farana region, Dubreka in Kindia region; Pita and Lelouma in Mamou and Labe regions respectively. Our study also revealed that $46 \%$ and $89 \%$ of pregnancies in Mamou in central Guinea were located outside $50 \mathrm{~km}$ and $25 \mathrm{~km}$ distance of a health facility respectively. This finding corroborates the report of 2012 Demographic and Health Survey (DHS) and Multiple Indicators Cluster Survey (MICS) ${ }^{37}$ which indicated that a higher proportion of women $(84 \%)$ in Mamou did not receive maternal healthcare after child birth which is crucial for the survival of the mother and newborn ${ }^{38}$.This is an indication of lack of adequate access to maternal healthcare services, which could be due to the long distance (of 50 and 25 kilometres) that the women had to travel to access healthcare. Furthermore, according to the $\mathrm{WHO}, 57 \%$ of health facilities were rated to be 'poor' in Guinea ${ }^{39}$. In addition, the same report found that there was a large concentration of health workers in the urban areas. For instance, $16 \%$ of the population live in the capital city of Conakry, but roughly half of all health professionals live there. There is therefore a major shortage of adequately trained health force, particularly in the rural areas. As one of the three countries largely affected by Ebola, and the first to have a recorded case, Guinea has been particularly affected by the disease. The first cases were recorded at Gueckedou, in Nzerekore region located in the south of the country. The region is near the borders of Liberia and Sierra Leone, and has been left impoverished by the civil unrest in Guinea, and the neighbouring countries. Its health infrastructure has also been severely damaged. Another unintended consequence of Ebola was that health workers have borne the brunt of infections: health workers were up to 32 times more likely to be infected ${ }^{40}$.

From the maps of Liberia (Figures $3 e$ and $f, 4 c$ and $5 c$ ), the distribution of women of reproductive age was high in most districts in Sinoe, Maryland and Grand Gedeh counties with the highest clustering found in Greater Monrovia. The results also showed that the maximum number of live births and pregnancies per grid square were lowest in the districts of Bokomu (Gbarpolu county), Butaw and Kpayan in Sinoe county, Morweh in Rivercess county; Salayea and Sasstown in Lofa and Grand Kru counties respectively. In addition, the high estimated percentage of pregnancies outside 50 kilometres and 25 kilometres of a health facility observed in the counties of Grand Gedeh, Grand Kru, River Cess, River Gee and Sinoe could indicate poor healthcare coverage and access exacerbated by the prolonged 14-year civil war in Liberia with its devastating effects on the country's healthcare system. Notably, Grand Kru, Rivercess and River Gee in south eastern Liberia have been identified as the poorest counties in the country with poor social and health indicators ${ }^{41}$. According to WHO situation health analysis, the number of nurses and certified midwives per health centre varies considerably across counties, with the rural counties in the south-east more likely to have the lowest staffing levels ${ }^{42}$.

Furthermore, it has been observed that in many rural southeastern towns of Liberia most roads become impassable during the rainy season from April to October and pregnant women seeking medical care had to trek for hours to the nearest clinic ${ }^{43}$. Following the outbreak of the Ebola virus, in 2014, the fragile healthcare system deteriorated and there was uneven distribution of health workers, with 60 percent of 
Liberia's health workers concentrated in Monrovia, where about 30 percent of the country's population lived ${ }^{44}$. Consequently, the people living in rural areas particularly were under-served; and as shown in our analysis one such area is Lofa county, located on the border with Guinea, which happened to be where the first Liberian Ebola case was recorded.

\section{Strengths and limitations of the study}

Our study has admittedly some limitations, and highlights further areas of work. In the main, our analysis did not include an exhaustive listing of health facilities (this would have required an inordinate amount of time and resources to locate all primary, secondary and tertiary health facilities), due to unavailability of data on emergency obstetric and newborn care in all the countries. In addition, calculation of standard or actual travel time is beyond the scope of this study. However, though there are uncertainties in the health facility and travel times data used in this study due to unavailability of comprehensive health facility data, the linkage of pregnancy data to datasets with the location of health facilities clearly showed that there were localities where increasing numbers of pregnancies and births have not been matched by commensurate increases in the availability of appropriate health facilities. This finding was also highlighted by the WorldPop project team ${ }^{2}$. This therefore suggests that inadequate maternal healthcare services and distribution of healthcare providers is leading to poor maternal health in these countries.

Another limitation is the fact that the majority of births (60\%) occur outside health facilities, and a significant proportion of these births are delivered without complications with the help of skilled and unskilled birth attendants ${ }^{45}$. However, the need for access to maternal and newborn care is important for emergency interventions when complications do arise, and geographical access becomes a barrier to safe motherhood ${ }^{15}$. Nonetheless, our study adds depth to the current knowledge from small area estimation of maternal and newborn outcomes by extending the work to subnational level (districts) in West Africa. Data generated would be useful for effective planning to promote safer pregnancies, births and healthier newborns and equitable distribution of human resources and infrastructure, thus bridging the gap in health inequity within and across the countries.

\section{Conclusions}

This study has revealed spatial variations in the distribution of women of reproductive age, pregnancies and births, and access to healthcare services at district levels in Mali, Guinea and Liberia., and this can be related to the numerous findings $11,46,47,48$ which have shown that proximity to health facilities is important in accessing maternal and newborn services. Our study found that in urban areas geographic distance does not appear to affect access to healthcare. However, in rural and remote areas, where transport infrastructure tend to be lacking and weak, there are geographic barriers to healthcare services. To bridge the gap in inequity in health care access and improve maternal and newborn health, there is need for equitable distribution of health facilities and health professionals in disadvantaged districts. Policy makers should prioritize allocation of resources and health infrastructure in these identified 
districts of the three countries particulaly districts in northern Mali, northern and forest regions of Guinea and counties in south eastern Liberia.

\section{Declarations}

\section{Acknowledgements}

The authors would like to thank the Caldwell Fellowship for funding this research; the School of Demography and National Centre for Epidemiology \& Public Health (NCEPH) at the Australian National University for their hospitality; and WorldPop at the University of Southampton for the permission to use their dataset.

\section{Funding}

This manuscript was developed while DO was visiting the Australian National University and funded through the Jack Caldwell Fellowship.

\section{Authors' contributions}

Study Design and Analysis: DO. Results summary and manuscript development: DO, BB, AR. Manuscript review: DO, BB, AR. All authors read and approved the final manuscript.

\section{Competing interests}

All authors declare that they have no competing interests.

\section{Consent for publication}

The manuscript does not involve human subjects.

\section{Ethics approval and consent to participate}

The manuscript does not involve human subjects and hence does not need ethical approval. The data used is all available in the public domain.

\section{Declaration}

None

\section{References}

1 Alkema L, Chou D, Hogan D, Zhang S, Moller AB, Gemmill A, Ma Fat D, Boerma T, Temmerman M, Mathers C and Say L. Global, regional, and national levels and trends in maternal mortality between 1990 and 2015, with scenario-based projections to 2030: a systematic analysis by the UN Maternal Mortality Estimation Inter-Agency Group. Lancet. 2016; 387 (10017): 462-74. 
2 Tatem AJ, Campbell J, Guerra Arias M, de Bernis L, Moran A, Matthews Z. Mapping for maternal and newborn health: the distributions of women of childbearing age, pregnancies and births. International Journal Health Geographics. 2014;13(1):2.

3 Salehi, F and Ahmadian, L. The application of geographic information system (GIS) in identifying the priority areas for maternal care and services. BMC health services research, 2017: 17:482.

4 Molla, Y. B., Rawlins, B., Makanga, P. T., Cunningham, M., Avila, J. EH., Ruktanonchai, C., Singh K, Alford S, Thompson M, Dwivedi V, Moran AC, and Matthews, Z. (2017). Geographic information system for improving maternal and newborn health: recommendations for policy and programs. BMC Pregnancy and Childbirth. 2017; 17(26), 1-7.

5 Gayawan, E. A poison regression model to examine spatial patterns in antenatal care utilization in Nigeria. Population, Space and Place. 2014. 20: 485-497.

6 Kazembe, L.N., and Namangale, J.J. A Bayesian multilevel model to analyse spatial patterns of childhood co-morbidity in Malawi. European Journal of Epidemiology. 2007. 22: 545-556.

7 Makanga PT, Schuurman N, von Dadelszen P \& Firoz T. A scoping review of geographic information systems in maternal health [published correction appears in International Journal of Gynecology \& Obstetrics 2016 Dec;135(3):388]. International Journal of Gynecology \& Obstetrics 2016;134(1):13-17.

8 Rahman, N. H., Rainis, R., Noor, S. H., \& Mohamad, S. M.. The Buffering analysis to identify common geographical factors within the vicinity of severe injury related to motor vehicle crash in Malaysia. World journal of emergency medicine, 2016, 7(4), 278-284.

9 Neal SE, Matthews Z: Investigating the role of health care at birth on inequalities in neonatal survival: evidence from Bangladesh. International Journal of Equity Health. 2013, 12: 17-10.1186/1475-9276-1217.

10 Amoako Johnson, F and Madise NJ. .Examining the geographical heterogeneity associated with risk of mistimed and unwanted pregnancy in Ghana. Journal of biosocial science. 2009. 41(2): 249-67

11 Ebener, S., Guerra-Arias, M., Campbell, J., Tatem, A. J., Moran, A., Amoako Johnson, F., Fogstad H, Stenberg K, Neal S, Bailey P, Porter R and Matthews, Z. (2015). The geography of maternal and newborn health: the state of the art. International Journal of Health Geographics, 14(1), 1-19.

12 Gao F, Kihal W, Le Meur N, Souris M, Deguen S. Assessment of the spatial accessibility to health professionals at French census block level. International Journal for Equity in Health (2016) 15:125

13 Ruktanonchai CW, Ruktanonchai NW, Nove A, Lopes S, Pezzulo C, Bosco C, Alegana V, Burgert CR, Ayiko R, Charles ASEK, Lambert N, Msechu E, Kathini E, Matthews Z and Tatem AJ. Equality in Maternal and Newborn Health: Modelling Geographic Disparities in Utilisation of Care in Five East African Countries. PLoS ONE. 2016. 11(8): e0162006. 
14 Fadahunsi JT, Kufoniyi O, Babatimehin OI. Spatial Analysis of Distribution Patterns of Healthcare Facilities in Osun State, Nigeria. Universal Journal of Public Health. 2017. 5(7), 331 - 344

15 Gething PW, Johnson FA, Frempong-Ainguah F, Nyarko P, Baschieri A, Aboagye P, Falkingham J, Matthews $Z$ and Atkinson PM. Geographical access to care at birth in Ghana: a barrier to safe motherhood. BMC Public Health. 2012;12:991

16 Bailey PE, Keyes EB, Parker C, Abdullah M, Kebede H, and Freedman L. Using a GIS to model interventions to strengthen the emergency referral system for maternal and newborn health in Ethiopia. International Journal of Gynecology \& Obstetrics 2011. 115(3):300-9.

16 Bailey PE, Keyes EB, Parker C, Abdullah M, Kebede H, and Freedman L. Using a GIS to model interventions to strengthen the emergency referral system for maternal and newborn health in Ethiopia. International Journal of Gynecology \& Obstetrics 2011. 115(3):300-9.

17 Hay SI, Noor AM, Nelson A, and Tatem AJ. The accuracy of human population maps for public health application. Tropical Medicine \& International Health. 2005. 10: 1073

18 Utazi CE, Thorley J, Alegana VA, Ferrari MJ, Takahashi S, Metcalf CJE, Lessler J, Tatem AJ. High resolution age-structured mapping of childhood vaccination coverage in low and middle income countries. Vaccine 2018. 36(12):1583-1591

19 https://www.worldpop.org/. World Pop. The University of Southampton Global Heath Research Institute. Accessed on 3 June 2019

20 Tatem, A.J, Noor, AM, von Hagen, C, Di Gregorio, A, and Hay, S.I. High resolution population maps for low income nations: combining land cover and census in East Africa. PLoS ONE. 2007. 2(12): e1298

21 Tatem AJ, Garcia AJ, Snow RW, Noor AM, Gaughan AE, Gilbert M and Linard C. Millennium development health metrics: where do Africa's children and women of childbearing age live? Population Health Metrics. 2013; 11: 11

22 https://data.humdata.org/. The Human Data Exchange. Accessed 3 June 2019

23 Datta. A., Sigdel, S., Oven, K., Rosser, N., Densmore, A., and Rijal, S. (2018). The role of scientific evidence during the $2015 \mathrm{Nepal}$ earthquake relief efforts. Overseas Development Institute. London, United Kingdom. https://www.odi.org/sites/odi.org.uk/files/resource-documents/12042.pdf. Accessed 3 June 2019

24 Williams, J. G., Rosser, N. J., Kincey, M. E., Benjamin, J., Oven, K. J., Densmore, A. L., Milledge, D. G., Robinson, T. R., Jordan, C. J., and Dijkstra, T. A. Satellite-based emergency mapping using optical imagery: experience and reflections from the 2015 Nepal earthquakes, Nat. Hazards Earth Syst. Sci., 18, 185-205, https://doi.org/10.5194/nhess-18-185-2018, 2018 
25 https://www.worldbank.org/en/country/mali/overview. Mali - country profile. The World Bank. Accessed 3 June 2019

26 Ministry of Health $(\mathrm{MOH})$ and Centre d'Etudes et de Recherches sur la Population et la Demographic (CERPOD): Rapport d'Analyse des Statistiques en SMI/PF au Mali en 1990. MOHKERPOD. Bamako. 1992.

27 World Health Organization. World Health Organization Fact sheet: Why is giving special attention to adolescents important for achieving Millennium Development Goal Five? 2008 Available from: http://www.who.int/making_pregnancy_safer/events/2008/mdg5/adolescent_preg.pdf. Accessed 3 June 2019

28 United Nations Population Fund (UNFPA). Annual Report. 2016.

Available. https://www.unfpa.org/annual-report-2016Accessed 3 June 2019

29 https://www.worldbank.org/en/country/guinea/overview. Guinea - country profile. The World Bank. Accessed 3 June 2019

30 WHO Ebola Response Team 2014. Ebola Virus Disease in West Africa - The First 9 Months of the Epidemic and Forward Projections. New England Journal of Medicine 2014; 371:1481-1495

31 Delamou A, Delvaux T, El Ayadi AM, Beavogui AH, Okumura J, Van Damme W, and De Brouwere V. Public health impact of the 2014-2015 Ebola outbreak in West Africa: seizing opportunities for the future. BMJ Global Health 2017;2:e000202

32 https://www.worldbank.org/en/country/liberia/overview. Liberia - country profile.The World Bank. Accessed 3 June 2019

33 Bernstein, L.. With Ebola crippling the health system, Liberians die of routine medical problems. 2014. The Washington Post. September 20, 2014. Available from https://www.washingtonpost.com/world/africa/with-ebola-crippling-the-health-system-liberians-die-ofroutine-medical-problems/2014/09/20/727dcfbe-400b-11e4-b03f-de718edeb92f_story.html? utm_term=.fdf205be3077. Accessed 3 June 2019

34 The World Bank - https://databank.worldbank.org/data/source/world-development-indicators. Accessed 3 June 2019.

35 Alegana, VA, JA Wright, U Pentrina, AM Noor, RW Snow, and PM Atkinson. Spatial Modelling of Healthcare Utilisation for Treatment of Fever in Namibia. International Journal of Health Geographics. 2012. 11 (1): 6.

36 International Committee of the Red Cross (ICRC) Report (2013). Mali: Access to healthcare remains challenging in the north.https://www.icrc.org/en/doc/resources/documents/update/2013/11-28-malihealth-care-in-danger.htm. Accessed 3 June 2019 
37 Demographic and Health Survey (DHS) - Guinea. Trends in Child Health in Guinea: Further Analysis of the 2005 and 2012 Demographic Health Surveys. Available from https://dhsprogram.com/publications/publication-FA95-Further-Analysis.cfm Accessed 3 June 2019

38 Institut National de la Statistique Ministère du Plan, [Guinée], MEASURE DHS and ICF International 2013. Demographic and Health and Multiple Indicators (EDS-MICS) 2012). Conakry Guinée, and Calverton, Maryland, U.S.A : Institut National de la Statistique Ministère du Plan and ICF International

39 Shoman H, Karafillakis and Rawaf S. The link between the West African Ebola outbreak and health systems in Guinea, Liberia and Seirra Leone: a systematic review. Globalization and Health 2017 13:1

40 World Health Organization (WHO). Ebola health worker infections. The African Regional Health Report: The Health of the People. World Health organization, Geneva. Available from https://www.who.int/features/ebola/health-care-worker/en/. Accessed 3 June 2019

41 Yaya S, Uthman OA, Bishwajit $\mathrm{G}$ and Ekholuenetale M. Maternal health care service utilization in postwar Liberia: analysis of nationally representative cross-sectional household surveys. BMC Public Health. 2019;19(1):28. Published 2019 Jan 8. doi:10.1186/s12889-018-6365- $x$

42 UNICEF. The situation of children and women in Liberia. Available from. https://www.unicef.org/overview_7939.html. Accessed 3 June 2019.

43 Kruk ME, Rockers PC, Williams EH, Varpilah ST, Macauley R, Saydee G and Galea S. Availability of essential health services in post-conflict Liberia. Bulletin of the World Health Organization. 2010. 88: 527534

44 Streifel, C. How Did Ebola Impact Maternal and Child Health in Liberia and Sierra Leone?: A Report of the CSIS Global Health Policy Center, 2015. Center for Strategic \& International Studies, Rhode Island, Washington DC. Available from https://www.csis.org/analysis/how-did-ebola-impact-maternal-and-childhealth-liberia-and-sierra-leone. Accessed 3 June 2019

45 Amoako Johnson, F. A geospatial analysis of the impacts of maternity care fee payment policies on the uptake of skilled birth care in Ghana. BMC Pregnancy and Childbirth. 2016. 16:41

46 Tatem, AJ. Mapping population and pathogen movements, International Health, 2014. Volume 6, Issue 1, Pages 5-11

47 Campbell, J., Sochas, L., Cometto, G., \& Matthews, Z. (2016). Evidence for action on improving the maternal and newborn health workforce: The basis for quality care. International Journal of Gynecology \& Obstetrics, 132(1), 126-129.

48 Bosomprah, S., Tatem, A. J., Dotse-Gborgbortsi, W., Aboagye, P., \& Matthews, Z. (2016). Spatial distribution of emergency obstetric and newborn care services in Ghana: using the evidence to plan interventions. International Journal of Gynecology \& Obstetrics, 132(1), 130-134. 
Figures

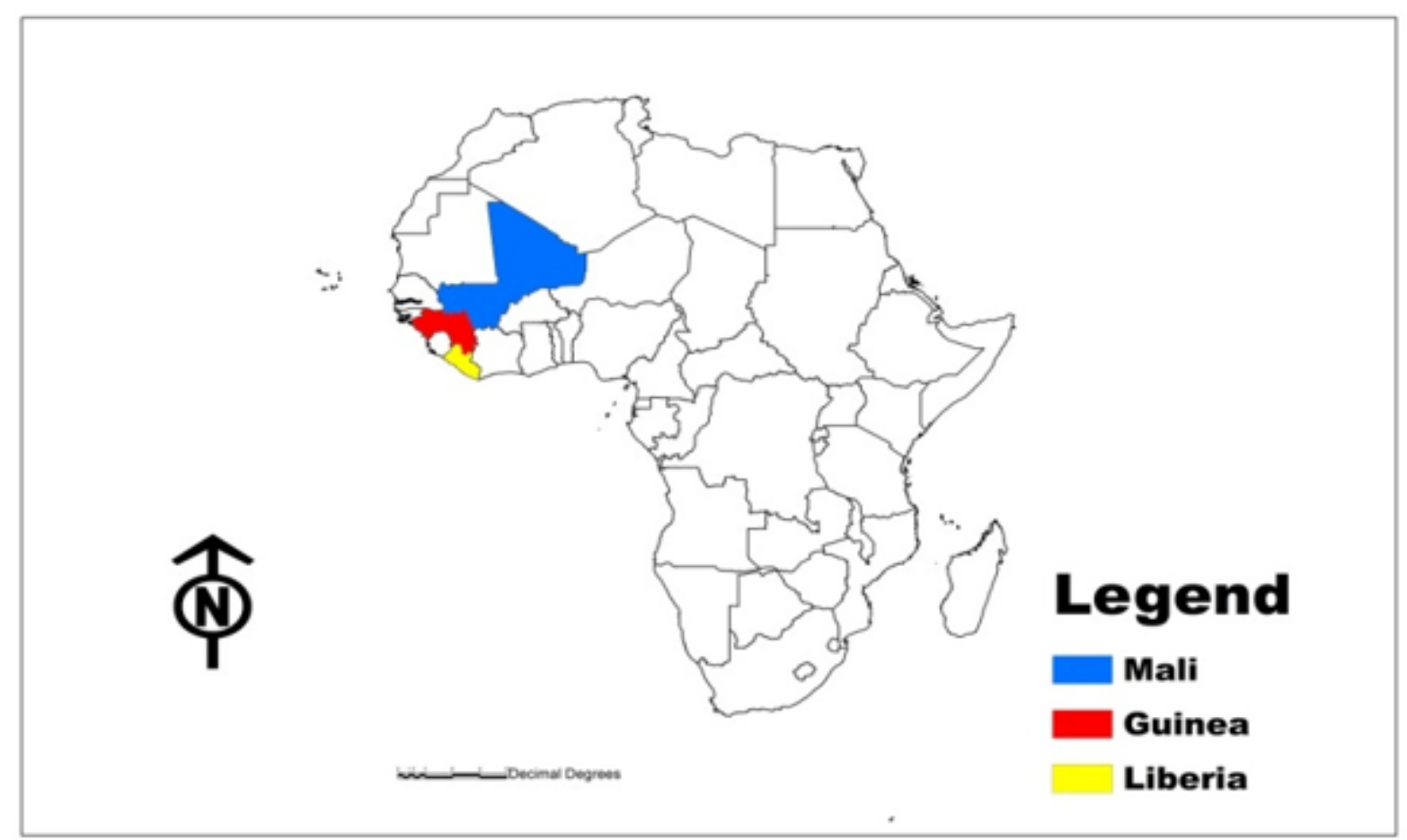

Figure 1

Map of Africa showing the three study countries (Mali, Guinea and Liberia). 


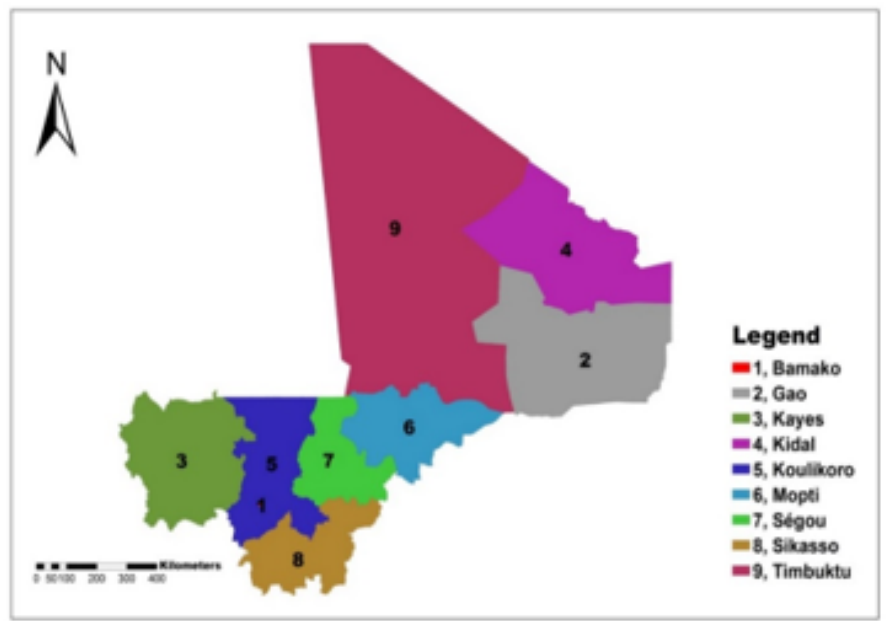

Figure 2(a) Regions in Mali

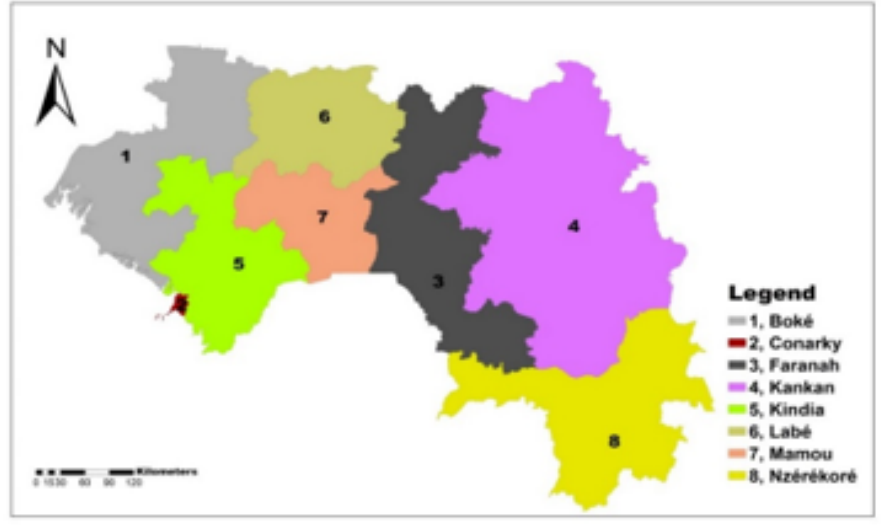

Figure 2(b) Regions in Guinea

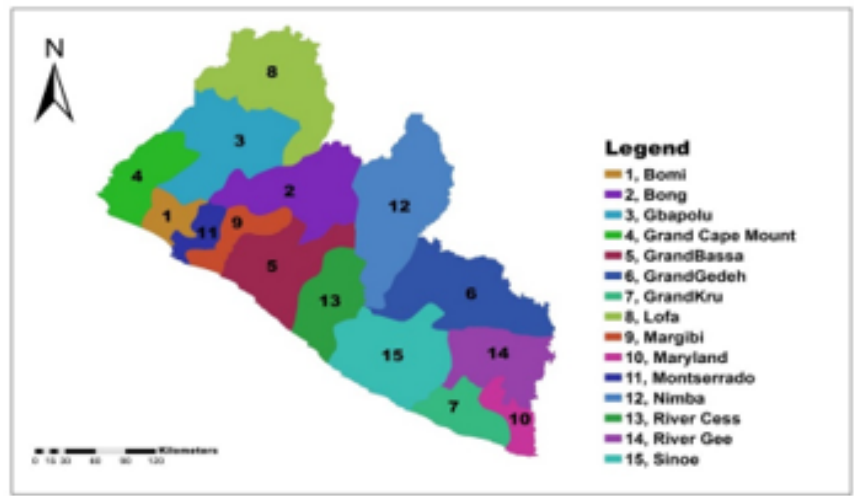

Figure 2(c) Counties in Liberia

\section{Figure 2}

Administrative geographies in Mali, Guinea and Liberia 
(a)

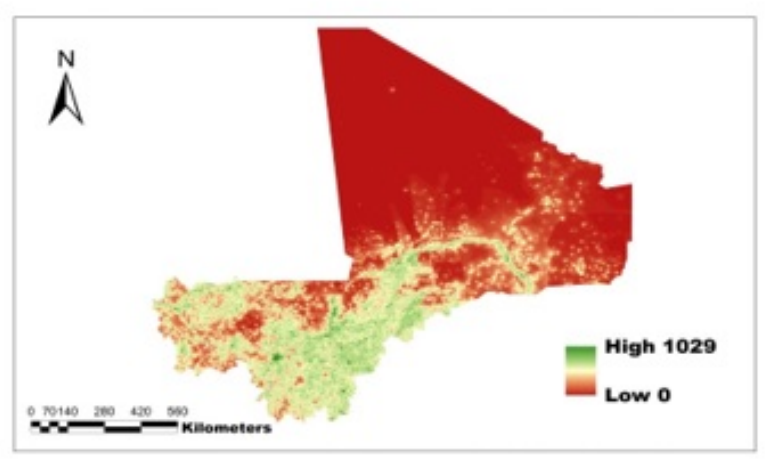

(b)

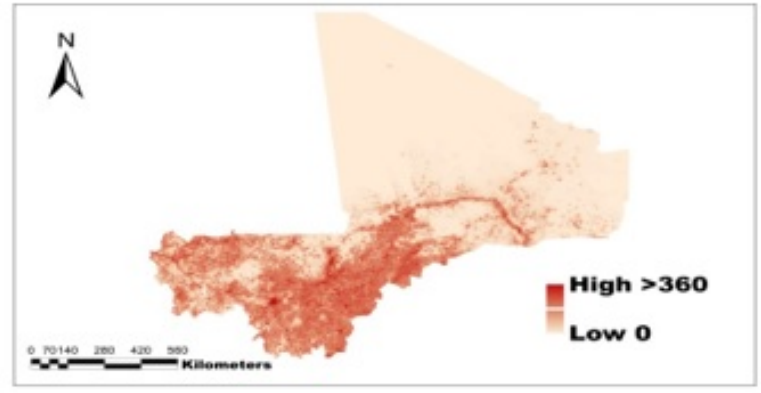

(c)

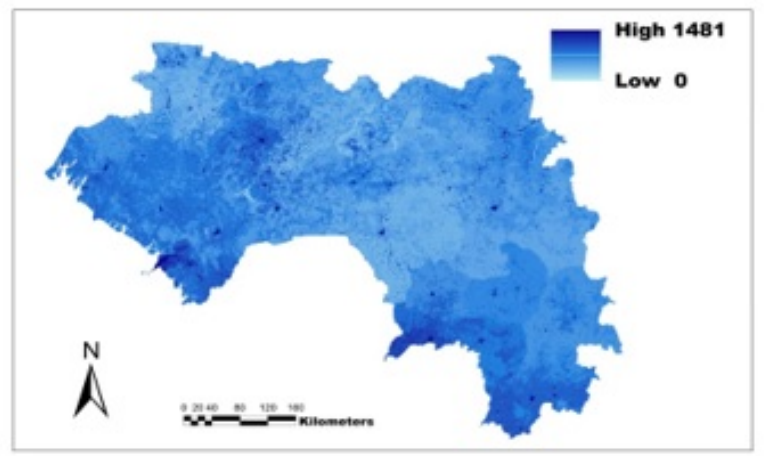

(d)

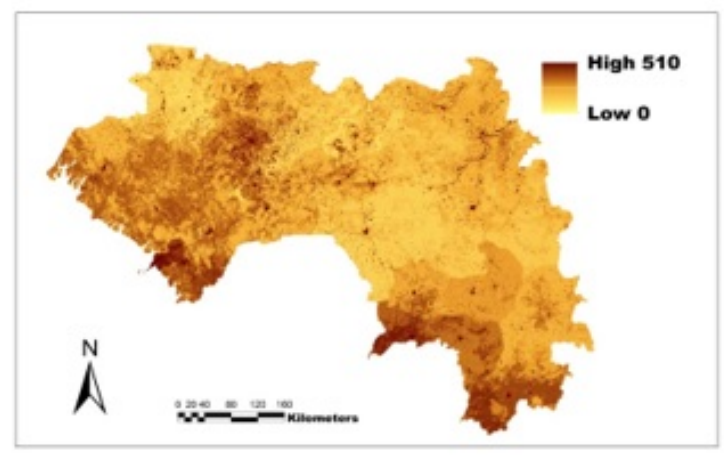

(e)

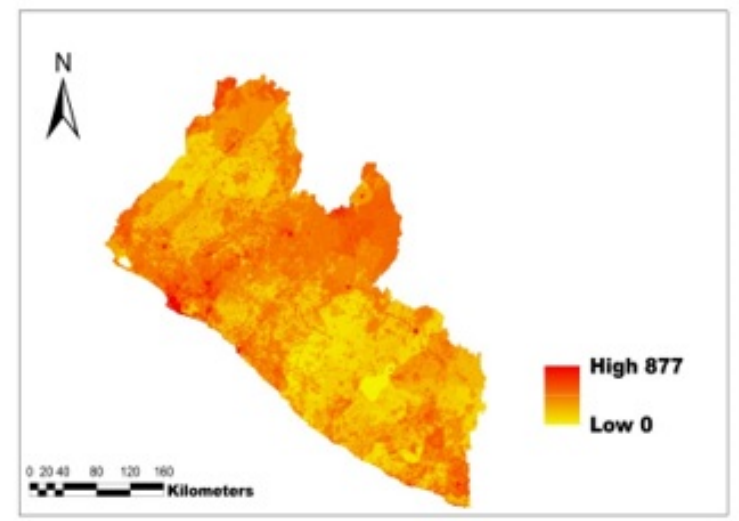

(f)

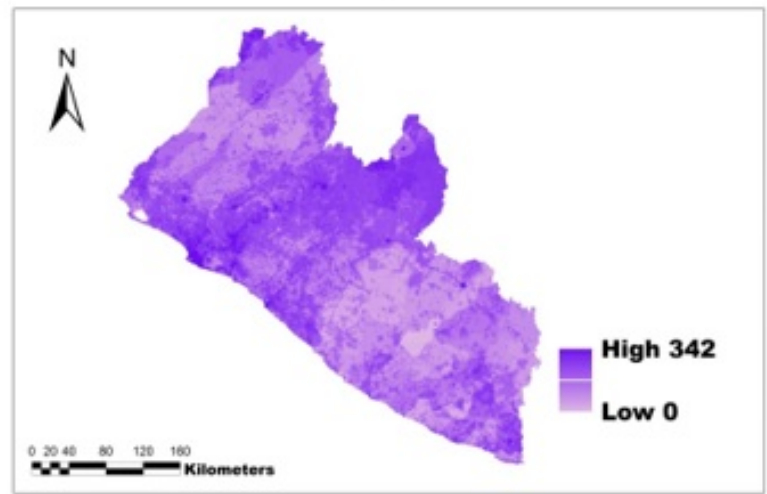

\section{Figure 3}

Spatial distribution of women of reproductive age Note: Population distribution map of Mali showing the number of women of reproductive age per $100 \times 100$ m grid cell: (a) 15-19 and (b) 40-44 Population distribution map of Guinea showing the number of women of reproductive age per 100×100 m grid cell: (c) 15-19 and (d) 40-44 Population distribution map of Liberia showing the number of women of reproductive age per 100×100 m grid cell: (e) 15-19 and (f) 40-44. 
(a)

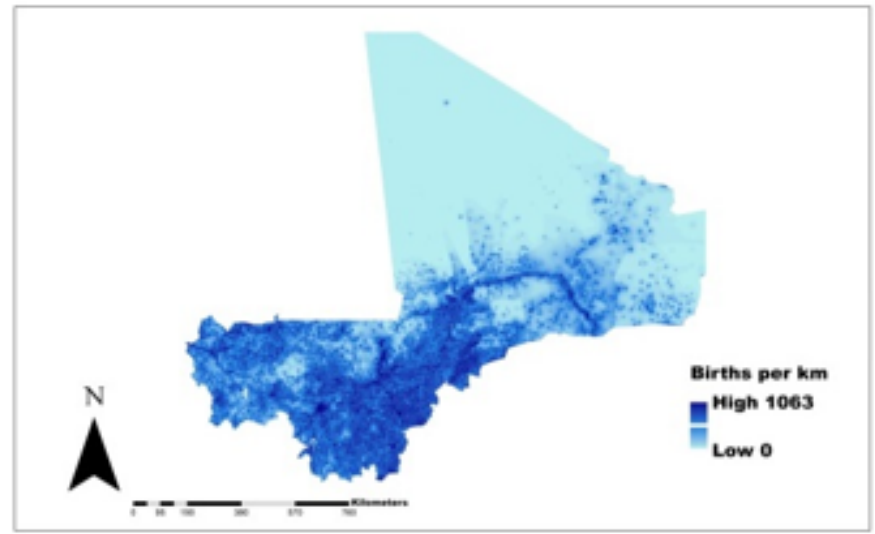

(b)

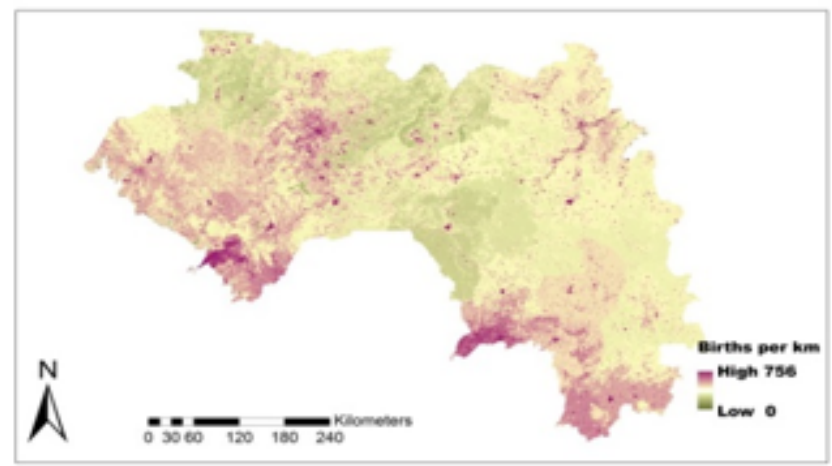

(c)

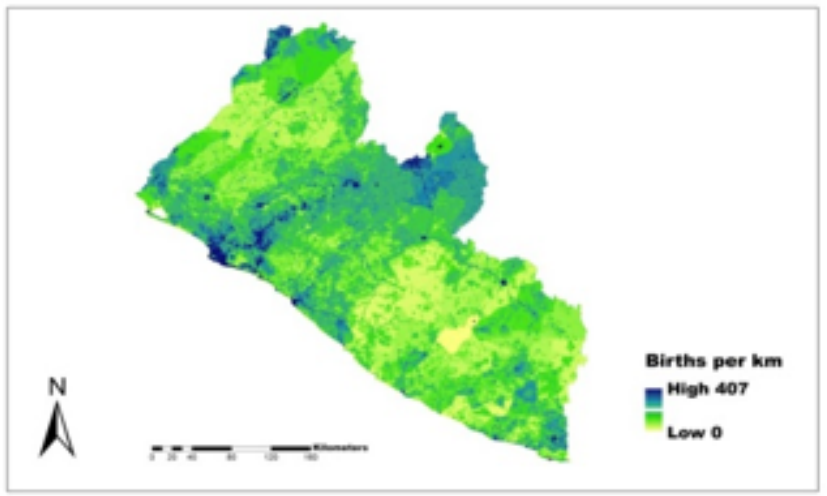

Figure 4

Distribution of the umber of live births per km2 (a) Mapped numbers of live births per square km for Mali (b) Mapped numbers of live births per square km for Guinea (c) Mapped numbers of live births per square $\mathrm{km}$ for Liberia 
(a)

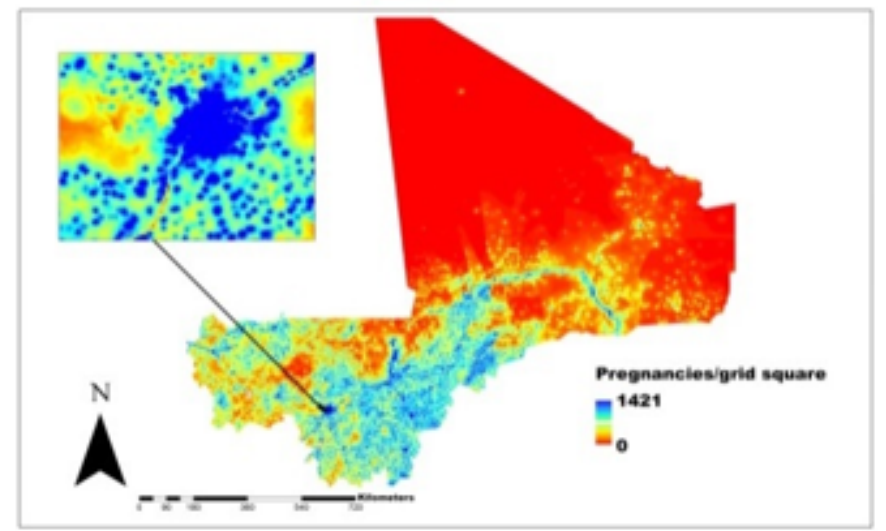

(b)

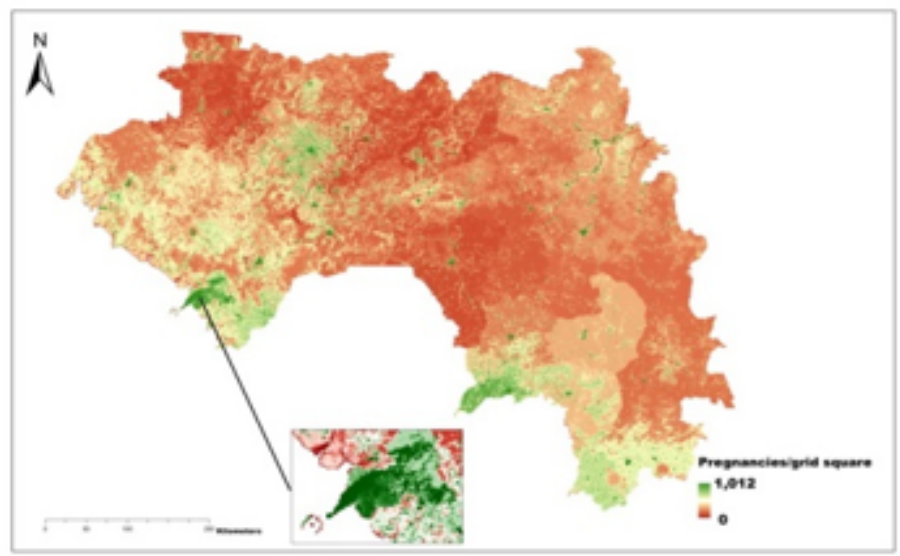

(c)

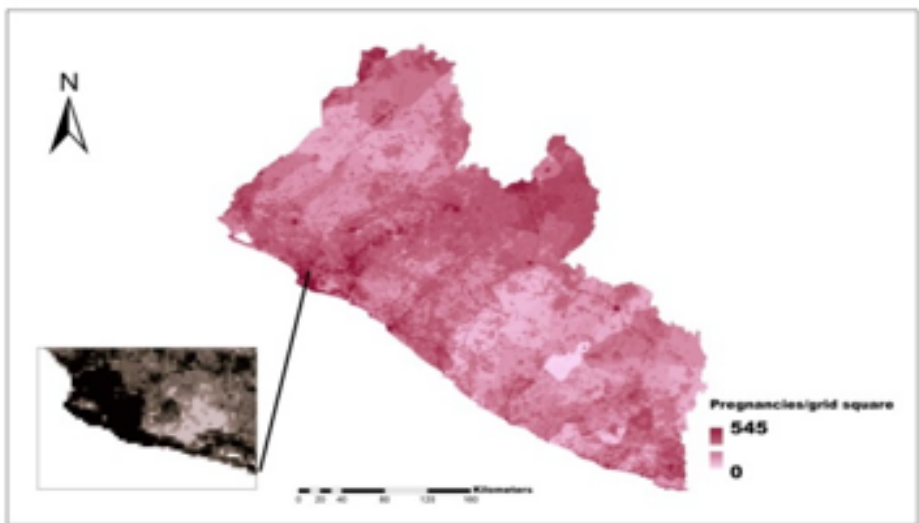

Figure 5

Estimated number of Pregnancies per grid square (a) Mali map, with a close up of Bamako area (b) Guinea map, with a close up of Conakry area (c) Liberia map, with a close up Greater Monrovia 
(a)

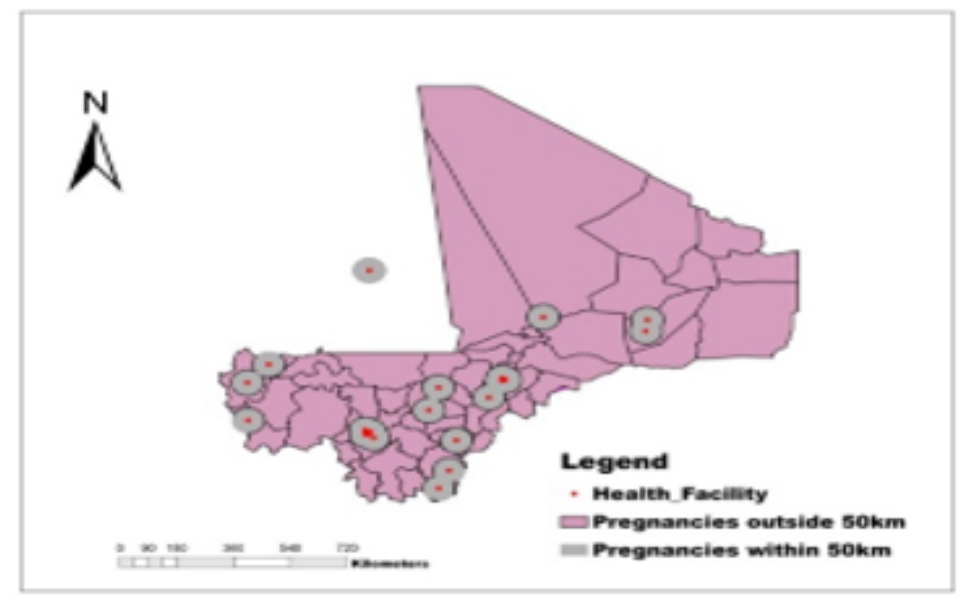

(b)

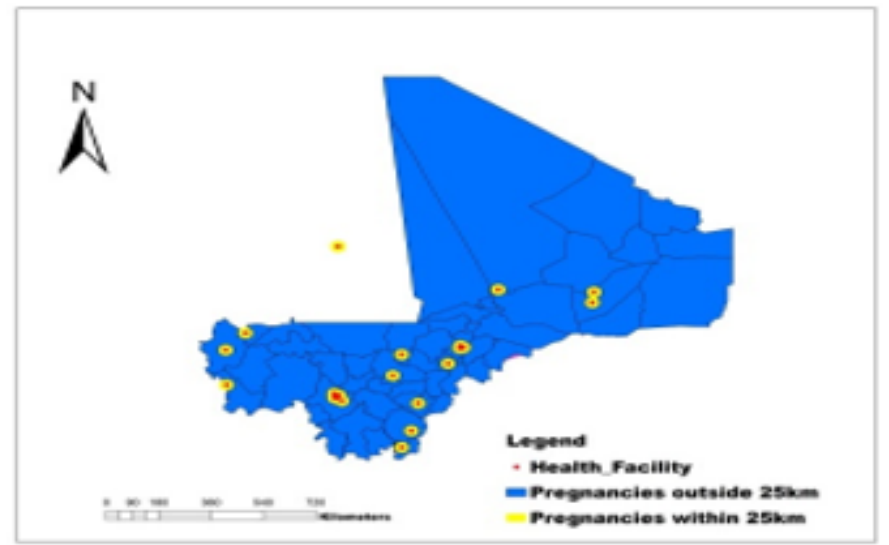

Figure 6

Proximity of pregnancies to health facilities in districts of Mali (a) Number of pregnancies within and outside $50 \mathrm{~km}$ of a health facility, (b) Number of pregnancies within and outside $25 \mathrm{~km}$ of a health facility 
(a)

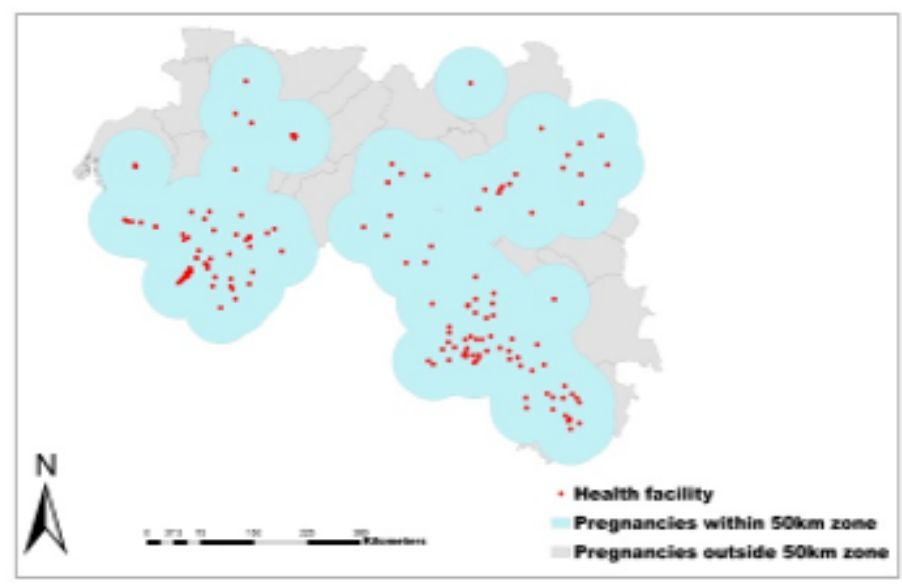

(b)

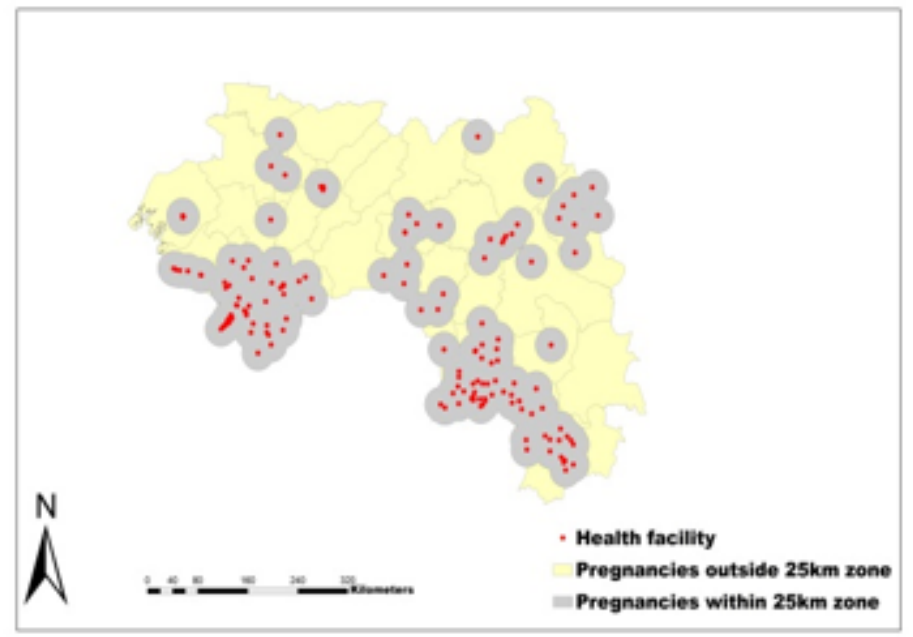

Figure 7

Proximity of pregnancies to health facilities in districts of Guinea (a) Number of pregnancies within and outside $50 \mathrm{~km}$ of a health facility, (b) Number of pregnancies within and outside $25 \mathrm{~km}$ of a health facility 
(a)

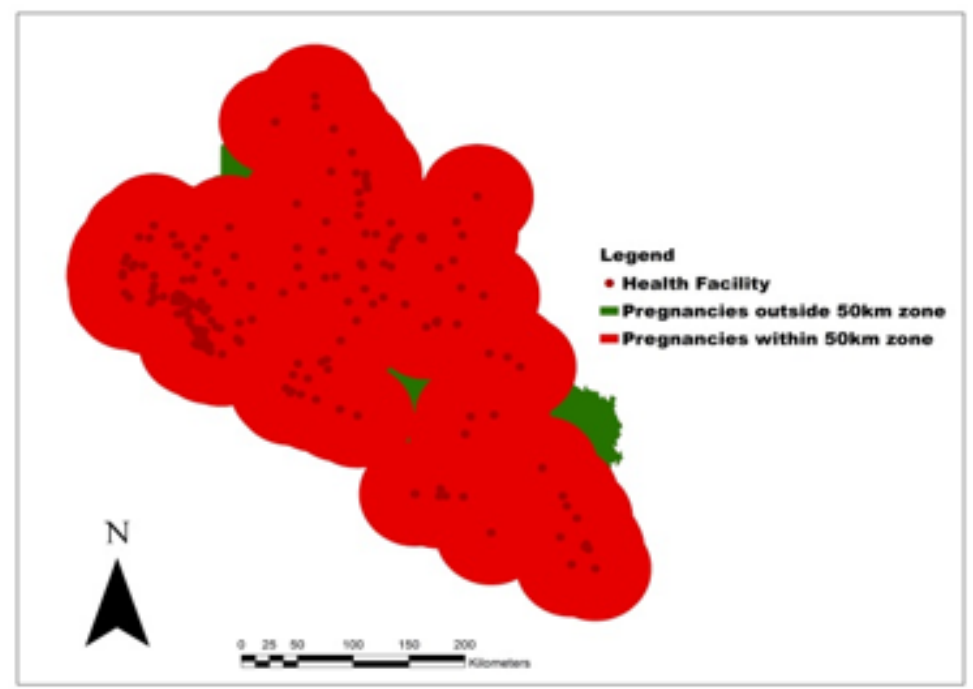

(b)

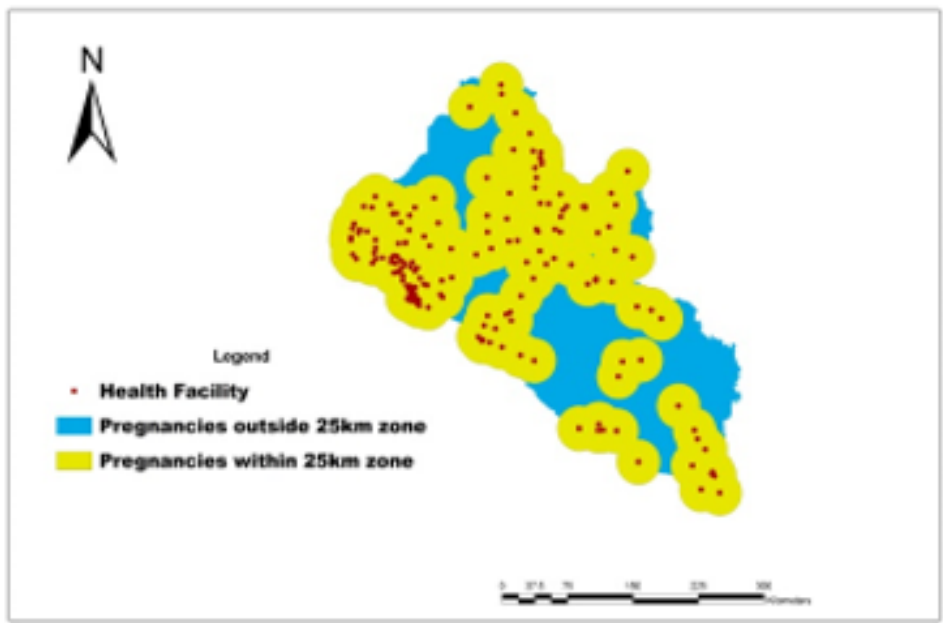

\section{Figure 8}

Proximity of pregnancies to health facilities in districts of Liberia (a) Number of pregnancies within and outside $50 \mathrm{~km}$ of a health facility (b) Number of pregnancies within and outside $25 \mathrm{~km}$ of a health facility 